\title{
A TEORIA PÓS-COLONIAL NO ENCONTRO DE DUAS NARRATIVAS
}

\author{
Izabel Cristina dos Santos Teixeira ${ }^{*}$ \\ Universidade da Integração Internacional da Lusofonia Afro-Brasileira
}

\begin{abstract}
Resumo: O objetivo deste trabalho é realizar uma leitura comparativa entre duas narrativas a novela "O coração das trevas" (1898), de Joseph Conrad e o filme "Apocalypse now" (1979), do diretor Franz Ford Coppola - tendo por base a teoria pós-colonial. O filme é tido como uma adaptação da referida novela, porém altera-lhe o espaço de contexto: no século XIX, o enredo se passa na África, durante o período de sua colonização; já no século XX, o cenário é a Ásia, durante a vigência da Guerra do Vietnã (1964-1973). Em cada um deles, novela e filme, evidencia-se a busca pela conquista territorial, pela imposição de forças, aparentemente desiguais. Neste sentido, é realçado o poder político e econômico dos países colonizadores, cada um a seu tempo, em espaços diferenciados (nos continentes africano e asiático), dando-se, no século XX, uma espécie de atualização ideológica da ocupação da África (realizado no século anterior), em que, uma vez abandonado o modelo de colonização ultramarina, leva-se à ascensão um novo formato desse sistema econômico, o qual, no último caso, tem por objetivo dar sustentação ao sistema capitalista norte-americano.
\end{abstract}

Palavras-chave: Colonização. Conflitos. Debate pós-colonial. Imperialismo.

\section{Introdução}

Em fins do século XIX, a Europa, por meio das Conferências de Berlim (1984-1985), decide pela ocupação da África, cujo cenário é explorado na novela "O coração das trevas" (1898), de Joseph Conrad.

O enredo se passa na época em que esse continente é alvo do interesse de uma das potências econômicas, a Inglaterra, que aí impõe sua ideologia colonialista, em busca da riqueza de então, no caso, o marfim.

\footnotetext{
* Doutora em Literatura (Universidade Federal de Santa Catarina). Área de atuação em Literatura e póscolonialismo.
} 
O filme "Apocalypse now" (1979), por sua vez, baseado na novela de Conrad, retoma, por assim dizer, o mesmo ideal de conquista, porém, de foram atualizada, na segunda metade do século XX, e traz, como pano de fundo, a "Guerra do Vietnã", vigente entre os anos de 1964 a 1973, na Ásia.

Essa atualização ideológica da ocupação da África se dá em um cenário, em que assistimos à decadência de um dos modelos de colonização ultramarino do século XIX, como é o caso do sistema francês, com sua mission civiliatrice, ao mesmo tempo em que vemos a ascensão de um novo formato desse sistema econômico que, desta vez, visa a atender às necessidades de expansão do sistema capitalista norte-americano, após a Segunda Guerra Mundial (1939-1945).

Após descrevermos as duas narrativas, elaboramos um diálogo com a teoria póscolonial, avaliando aspectos do sistema colonialista europeu de além-mar, na África, seu estágio de decadência, na África e na Ásia, culminando com o domínio imperialista norteamericano neste último continente.

\section{As narrativas}

"O coração das trevas" e "Apocalypse now" exibem quadros das ações praticadas pelas Metrópoles colonizadoras, as quais ignoram as peculiaridades culturais de cada um dos lugares em que estão presentes, quando inscrevem, ali, suas marcas "ocidentalizantes" e imperiais.

A partir de exemplos levantados no resumo das histórias, temos um inventário de tensões que envolvem interesses colonialistas, em nome da expansão de suas fronteiras.

\section{A novela "O coração das trevas"}

O enredo se refere à história de Charlie Marlow, marinheiro experiente que, tendo viajado por muitos mares do mundo, está em um navio de Cruzeiro, o Nellie, com outros passageiros a bordo, passeando no Rio Tâmisa, em volta da cidade de Londres. A esses passageiros ele relata sua história de como se tornou comandante de uma embarcação a serviço de uma Companhia de Exploração de marfim, na África. Após acertos de praxe - que incluíam uma consulta médica com recomendações sobre as alterações psicológicas no comportamento de homens que iam ao "Continente negro", devido às peculiaridades do lugar, 
e de uma recepção comemorativa pela empreitada - ele segue, com a missão de trazer de volta Kurtz, um comerciante desertor da mencionada companhia. Este, que havia se destacado para o trabalho, após redigir um relatório para a "Sociedade Internacional para a supressão dos costumes selvagens", na vigência do trabalho realizado pela Companhia exploradora, passa a fazer contrabando de marfim, cooptando nativos, com a ajuda de um marinheiro russo. $\mathrm{Na}$ viagem empreendida à África, Charlie Marlow descortina uma série de passagens que vão, desde o tratamento desumano dado aos nativos, até assassinatos, roubos e instalação de empresas fictícias, que pilham os bens naturais dos africanos. Além disso, descreve outras mazelas, até atingir, no percurso de sua viagem por um grande rio local, o "coração das trevas". Encontrando-se com Kurtz, recebe dele algumas recomendações, documentos e uma foto a ser entregue à sua "Prometida", quando voltasse à Inglaterra. Após esse encontro, Kurtz agoniza, pronunciando as palavras "O horror! O horror!". Ao mesmo tempo em que Marlow conclui a história narrada aos passageiros, o navio Nellie retorna a Londres.

\section{O filme "Apocalypse Now"}

O filme traz a história do capitão Willard, convocado para uma missão secreta no Camboja (Ásia). Sua missão consiste em eliminar o coronel Walter E. Kurtz, militar que, antes, servindo aos interesses dos EUA, percebe que a Guerra da qual participa é um arranjo irresponsável e sem nenhuma possibilidade de ser vencida. Kurtz, após descobrir uma conspiração promovida por agentes duplos, mata-os, sendo, por isso, perseguido como assassino de guerra. Diante desta e de outras situações, decide formar um contingente guerrilheiro particular, que provoca assassinatos em quaisquer lados da guerra. Willard segue em busca de seu objetivo, em barco de marinha, pelo Rio Nung, acompanhado de indivíduos civis americanos, em sua maioria, despreparados e pouco esclarecidos sobre a realidade da guerra. Na subida pelo rio, o grupo depara-se com acampamentos sem qualquer estrutura militar, até alcançar o Camboja, onde encontra uma missão francesa ali estabelecida, há quase um século. Saindo de lá, Willard encontra Kurtz, de quem, inicialmente, torna-se prisioneiro. Libertado, Willard, passado algum tempo, cumpre a missão: mata violentamente Kurtz, ao mesmo tempo em que este pronuncia as palavras "O horror! O horror!".

\section{Diálogo das narrativas com a teoria pós-colonial}


A novela é contextualizada na segunda metade do século XIX, em plena vigência da Revolução Industrial, ocorrida na Inglaterra. Edward Said (1990, p. 19) lhe reconhece o mérito de ter sido a primeira, de uma série de obras literárias, surgidas na época, a enfocar relações de domínio, no sistema colonialista. Assim, "O coração das trevas" aborda o conflito entre colonizador-colonizado, a partir de um eixo dicotômico. Em suas próprias palavras, o autor afirma que "cabe a Conrad o enorme crédito de ter vibrado, numa prosa profundamente complexa e dilacerada, a autêntica nota imperialista, embora tudo que consiga ver seja um mundo totalmente dominado pelo ocidente atlântico" (SAID, 1990, p. 96), ou seja, para Said, o ficcionista não demonstra qualquer posicionamento crítico contra as ideologias dominantes de seu tempo.

$\mathrm{Na}$ obra, identificamos a perspectiva do "pretexto da hegemonia cultural européia" para formar uma imagem degradante do povo africano, situação que pode ser exemplificada na passagem do texto em que uma senhora da sociedade londrina, na recepção comemorativa à empreitada colonizadora, fala a Charles Marlow que sua missão na África irá "arrancar aqueles milhões de ignorantes de seus horríveis costumes" (CONRAD, 2003, p.46). Tal concepção que, aos olhos de Said (1990, p. 20), é ironicamente referida como "filantropia imperialista", na prática, é entendida por ele como um exemplo de exercício de poder e de interesses. Ou seja, a Metrópole colonizadora, a partir de uma lógica de oposições binárias, caras às atividades nacionalistas e imperialistas, se vê como "altruísta e indispensável, diante de uma África ignorante e débil mental", nos termos colocados pelo próprio ensaísta, sobre a novela de Conrad. Suas constatações confirmam o pensamento de Memmi (1977, p.23) para quem "a caracterização do colonizador é a de quem tem um grande papel a desempenhar no processo da colonização, fazendo o bem", quando, na verdade, o que o colonizador tem em mente é a "usurpação: tomar tudo do colonizado".

$\mathrm{Na}$ menção feita à lógica binária colonialista, podemos citar uma passagem do texto em que o médico que atende a Marlow lhe diz: "sempre peço permissão, no interesse da Ciência, para medir os crânios daqueles que se aventuram até lá (...)"; e mais: "tenho uma pequena teoria, que os senhores que vão para lá devem ajudar-me a confirmar. Essa é a minha parcela de contribuição que o meu país há de colher na posse de uma colônia tão magnífica (...)" (CONRAD, 2003, p. 34).

A questão do pensamento forjado no meio urbano, com sua presunção de superioridade cultural, intelectual e científica do indivíduo colonizador, nos leva à contrapartida crítica feita por Franz Fanon em seu livro "Os condenados da terra” (1973). Para ele, 
"o negro nunca foi tão negro quando a partir do momento em que foi dominado pelos brancos" (FANON, 1973, p. 212), assertiva que denuncia, ao mesmo tempo, preconceitos étnicos e exploração de força de trabalho, perpetradas pela idéia fomentada nos grandes centros do continente europeu, vigentes na época em que o ensaio mencionado acima foi publicado. Corroborando com Fannon, o filósofo africano Kwame A. Appiah dirá que "a idéia da própria categoria do negro é, no fundo, um produto europeu, pois os brancos inventaram os negros a fim de dominá-los" (APPIAH, 1997, p. 96). Assim, na ficção, a questão colocada pelo médico (branco e ocidental) se sustentará por um discurso pretensamente científico sobre o continente africano, cuja imagem é reduzida à objetificação.

Em um outro ensaio, "Peles negras, máscaras brancas” (1975), Fanon já havia avaliado esse aspecto da questão colonial, a partir de estudos realizados por O. Manoni, apresentados no trabalho "Psycologie de la colonisation" (MANONI apud FANON, 1975, p. 34). Para Fanon, seu colega psiquiatra percebe que a colonização é mal depreendida em suas verdadeiras coordenadas, porque o "seu estudo comporta outras relações (condições objetivas e históricas) e a atitude do homem a respeito dessas condições”. Além disso, para Fanon (1975), quando a "ciência branca" patologiza o conflito da colonização, obviamente, o colonizado (que, no caso da novela de Conrad, é o negro africano) sai em franca desvantagem, porque a "conclusão branca" de O. Manoni é a de que "o colonizado traz em si, desde a infância, um germe de inferioridade" e esse nada mais é do que um pensamento produzido por uma sociedade racista, uma vez que "a Europa tem uma estrutura social racista e adota esse modelo em suas colônias" (FANON, 1975, p. 105) e, por conseguinte, está na base de outros pensamentos a respeito da inferioridade do negro.

À medida que a narrativa avança para alcançar o "coração das trevas (África)", as cenas vão denunciando a prática, não só do racismo, mas, também, de escravagismo, como nesse exemplo: "Seis negros avançavam enfileirados (...). trapos pretos estavam dispostos em torno de seus lombos (..). Cada um levava uma argola de ferro no pescoço, e estavam todos atados entre si por uma corrente (...)" (CONRAD, 2003, p. 38).

Considerando que a novela, escrita num período de colonização em que o sistema de escravidão inglês estava chegando ao fim, esta parte da narrativa dá a entender que havia desmandos na colônia, onde a "exploração do colonizado se deu com muita violência, e foi essa violência que presidiu o arranjo do mundo colonial", conforme nos confirma Fanon (1983, p. 30-31), pois está assentada em uma lógica maniqueísta que desumaniza o colonizado. Nos termos de Ania Loomba, diremos que, nesse caso, os negros são vistos como 
uma massa indistinta, pois a individualização dos sujeitos ocorrida na Europa, por exemplo, foi negada aos colonizados. Para a autora, "nas colônias, os europeus confiavam mais no poder coercitivo da força do que no eufemístico exercício "produtivo" de poder, mais típica da metrópole" (LOOMBA, 1998, p. 52).

Sobre a novela de Conrad, podemos observar, também, a facilidade com que o colonizador enriquecia, pilhando a colônia. Assim sendo, "na colônia ganha-se mais, gasta-se menos, alcançando altos ordenados, carreiras mais rápidas, negócios mais rendosos" (MEMMI, 1977, p. 22). Com isso, vemos que as ações humanas tornam evidentes as ambigüidades assinaladas por Said que destaca a "força redentora da colonização e a própria devastação e horror dessa missão no mundo negro - o coração da África" (SAID, 1990, p.55). Ele percebe que a narrativa, ao que parece, funciona dentro dos interesses imperialistas, como se a região africana não fosse habitada, levando-o a crer que possivelmente Conrad sequer conhecesse a África, uma vez que não estabeleceu quaisquer "contrapontos" em sua obra, em relação a autores africanos, contemporâneos de sua produção narrativa. Pelo fato de o ficcionista limitar-se às afirmações de senso comum, Said, contestando-o, afirma que os equívocos na apresentação dos "colonizados” por Conrad levam à conclusão de que o autor é um homem do seu tempo, no sentido de que "ele acreditava que a África era incapaz de independência e que os ingleses poderiam ajudar aos africanos e que esses precisavam dessa ajuda" (SAID, 1990, p. 64).

Ao integrarmos o filme "Apocalypse Now" à teoria pós-colonial, lembramos que Robert Stam (2003) menciona a influência desses estudos ao cinema, após os anos de 1960. Para ele, Fanon é um dos teóricos anti-colonialistas mais respeitados, por manter viva a representação do poder do colonizador, francês, na Ásia: “O colono faz a história. Sua vida é uma odisséia. Ele é o começo absoluto" (STAM, 2003, p. 117).

Assim, filme em questão é uma espécie de parábola sobre o imperialismo e, certamente, é uma atualização, após a Segunda Guerra Mundial, do rastro deixado pela colonização européia na África, desde o século XIX. É, também, é a primeira reflexão sobre o processo aviltante da "missão civilizadora" que franceses levaram para a região do Camboja, na Ásia, ainda um pouco antes de o Vietnã se tornar o lugar-alvo de interesse e conquista dos norte-americanos. Entre estes lugares, num cenário de guerra, o Capitão Willard, sai pelo Rio Nung, até alcançar o objetivo final: assassinar o Coronel Kurtz.

Nesse lugar, a presença de soldados norte-americanos impõe ações destrutivas sobre uma população que reage contra uma lógica maniqueísta que lhe é desfavorável. Na tentativa 
de conquistar esse outro lado do mundo, é possível identificar o interesse, tanto de franceses quanto de norte-americanos, em modificar práticas e costumes da população local, para ajustá-los aos arranjos de seus interesses coloniais, sem levar em conta a diversidade étnica da população autóctone. Ou seja: para sustentar seu "direito" de dominar, esses colonizadores desenvolvem argumentos que lhes justificam a necessidade de sua presença ali, praticamente, nos mesmos termos que os ingleses na África. Por tanto, apresentam idéias negativas quanto ao colonizado e tudo que lhe diz respeito.

Dessa forma, no filme, a soberania colonialista se apresenta em três cenas-chaves: a primeira cena: - a família da mission civiliatrice - francesa, ali instalada há 79 anos, protegida por um exército para-militar e pelas elites locais. No encontro do capitão Willard com os franceses, no Camboja, em meio a um jantar, um deles, cidadão francês, lhe diz que, até a chegada da missão, os "vietnamitas não sabiam de nada" - o que mostra a ação paternalista da família francesa, que ali está para enriquecer e ter todos os direitos.

A fala do colonizador francês - "essa terra fomos nós que fizemos"- nos remete a Fanon (1975), para quem o colonizador via a colônia como um prolongamento da Metrópole, isto é: ele faz a história de sua nação no território explorado. Não nos admira que o colonizador não deseje voltar para a Metrópole, e acaba por se auto-caracterizar como alguém que tem grande papel a desempenhar no processo de colonização, fazendo o bem. O próprio Memmi (1977), criticando tal aspecto da exploração colonial, cita um exemplo que lhe é próximo: a missão francesa na Tunísia, seu país de origem, se preocupava em garantir apenas vantagens econômicas. Por extrapolação, o mesmo se dá na Ásia e, aí, observamos que o "colonizador se beneficia com a mão-de-obra (criadagem numerosa e pouco exigente), pois o colonizado é explorável impunemente e não se acha protegido por leis da colônia" (MEMMI, 1977, p. 24).

Com plenos poderes, o colonizador vai destruindo o sistema tradicional da economia e o modo de vida camponesa do asiático, por meio da substituição da produção agrária local pelo plantio de árvores seringueiras, do qual se extrai o látex para a produção da borracha, ação que não traz quaisquer benefícios para os habitantes do lugar, mas para o colonizador, e para sua concepção de cultura e de progresso.

Ao mesmo tempo em que o paternalismo dos colonizadores franceses promove o desmonte do sistema educacional vietnamita, ao lhe dar instrução de conhecimentos do ocidente; coopta as elites do país (forma um exército paramilitar; o prefeito da cidade proíbe que os nativos exponham roupa lavada na rua, por exemplo), tudo isso confirmando a análise 
que Loomba (1998, p. 52) faz do colonizador. Este, por meio de força coercitiva, acreditava que poderia modificar séculos a fio de um padrão cultural edificado naquela região.

Um outro aspecto, não exatamente a favor do colonizador, que se sobressai no filme, ainda na cena do diálogo, durante o jantar oferecido ao capitão Willard e sua comitiva, é a informação distorcida sobre a derrota do modelo colonialista francês que culminou com a perda política, tanto da Indochina, ali mesmo, na Ásia, quanto da Nigéria, na África. O episódio é analisado por Said que entende, como resposta ao cinismo hipócrita do sistema colonialista, o próprio curso da História como contraponto: todos eles acabam subestimando suas posses, pois, segundo o autor, "nenhum projeto desse porte jamais deu certo, por que envolve planejadores em mais ilusões de onipotência e enganosa satisfação consigo próprios" (SAID, 1990, p. 20).

$\mathrm{Na}$ Ásia, os franceses não conseguem articular a fala que traduza a realidade para si mesmos: culpam os americanos por terem feito a França perder o poder sobre a Indochina; culpam o próprio governo francês (referem-se ao presidente socialista Mendes-France) pela derrota de seu exército na Ásia. Cheios de "instinto colonizador", formulam todas as possibilidades inúteis, para não enxergarem que estão diante de um processo histórico que segue em frente. Sua percepção é tão falha, que não se dão conta de que, no próprio país-sede da colonização, a França, nos anos da guerra do Vietnã, insurge-se, contra este modelo econômico, o movimento feminista - "Mulheres francesas contra a presença da França no Vietnã". Este movimento, destacado em imagens de uma passeata, dá visibilidade à opinião pública de contestação, fato não verificado na novela de Conrad (século XIX), em que a sociedade estabelecida não se opunha à prática colonizadora, pelo contrário, confirmava e aplaudia esse modelo de relação social, econômica e política.

A segunda cena-chave: - o "arranjo" forjado para a eliminação do coronel Walter E. Kurtz pelo capitão Willard. Este, após acertos e reparos com o grupo que o contrata, sem nada contestar, segue para a missão. Esta, uma vez cumprida, deverá ser apagada de sua memória e da memória da História (Willard deverá destruir quaisquer evidências de sua missão), trazendo à tona a idéia de que apagar registros históricos (provas documentais da ocorrência de fatos) é, também, uma prática manipuladora imperialista, direcionada aos seus fins, tanto políticos quanto econômicos.

A terceira cena-chave: - contratação de um serviço de inteligência que vende informações ao governo americano - a Rand Corporation, cujos dirigentes já haviam destruído o comunismo na Malásia. Estes irão informar ao governo norte-americano como 
ganhar a guerra em andamento no Vietnã. Willard, durante o almoço em que agentes do Governo americano - entre militares e civis - lhe dão os detalhes de sua participação na missão assassina, não é informado, nem de tal organização, nem de suas manobras. Essas zonas de apagamento/descontinuidade de ações - como se Willard fosse apenas mera peça de uma engrenagem - são, provavelmente, mais um meio de reforçar a construção do estereótipo de superioridade de "brancos" sobre "amarelos" (asiáticos, no caso): os americanos tentam, com tal atitude, impedir, no futuro, a possibilidade de reconstituição histórica de suas ações na Ásia.

Somando-se todos os dados levantados, alcançamos, ainda que fora do ordenamento seqüencial do filme, o acontecimento do jantar que franceses aos recém-chegados: aí se dá, na verdade, o encontro das duas ideologias de dominação - a norte-americana e a francesa respectivamente, imperialismo e colonialismo: ambas, sem possibilidade de um diálogo, em qualquer nível que seja, pois, conforme Said, "foram colocadas, em convívio, visões e experiências, ideológica e culturalmente, fechadas uma à outra, e que tentam afastar ou eliminar outras visões e experiências" (SAID, 1990, p. 66). De ambos os lados, as experiências são tão díspares que não há como interagir, na busca de quaisquer esclarecimentos. Os franceses estão ali para usurpar os bens dos nativos e manter sua família unida, de forma bem particular; os norte-americanos, para realizar uma fase das muitas etapas de um processo de expansão imperialista.

Ao fim, após cumprir sua missão, o Capitão Willard retorna ao Barco americano, deixando para trás o cenário de uma grande barbárie ocorrida na segunda metade do século XX.

\section{Atando as pontas...}

O conjunto da obra de Conrad tem sido lembrado por Said como um exemplo de análise do processo colonialista europeu na África. Entretanto, para o próprio ensaísta, Conrad, como ficcionista, nada mais foi do que um homem do seu tempo, no sentido de não ver outro horizonte para as colônias, que não fosse o da colonização, tendo, assim, apontado para o inevitável: o domínio do império colonial, como resultado das concepções ocidentais sobre o terceiro mundo. Nesse caso, por mais que tenha detalhado na novela a crueldade aplicada ao nativo africano, Conrad permaneceu com suas referências "brancas" e "ocidentais", fazendo crer - via ficção - que cabia aos europeus dizerem o "que é um bom ou 
um mau nativo, já que eles possuem existência suficiente dentro da lógica de reconhecimento branco e ocidental" (SAID, 1990, p. 19). Com ironia, Said assume essa "fala branca" de Conrad e a próxima: "Nós os criamos, nós os ensinamos a falar e a pensar, e quando se revoltam eles simplesmente confirmam nossas idéias a respeito deles, como crianças tolas, enganadas por alguns de seus senhores ocidentais" (SAID, 1990, p. 19). Assim sendo, Said (1990, p. 19) conclui que o novelista não acreditava que a África ou a América do Sul pudessem, algum dia, ter uma história ou uma cultura independentes. Porém, o curso da História nos revela que os imperialistas do século XIX realizaram sua empreitada, mas foram, afinal, derrotados (conforme vimos na atualização do filme "Apocalypse Now”).

Se o "Coração das trevas" permite que o leitor veja o colonialismo como um sistema em que um modo de vida é subordinado à experiência marcada por loucuras e ações do campo dominante, como parece ser o que Conrad nos insinua, então, no filme, apesar da derrota desse sistema colonialista europeu, o discurso do poder "branco" prova que o embate imperialista oitocentista ainda continuou a traçar novas linhas. Ou seja, os ocidentais "podem ter saído fisicamente de suas antigas colônias na África e na Ásia, mas as conservam não apenas como mercados, mas também como pontos no mapa ideológico onde continuaram a exercer domínio moral e intelectual” (SAID, 1990, p. 58). No caso do filme, este papel já estava em poder dos norte-americanos que haviam conquistado a Malásia, a Coréia e as Filipinas, países da Ásia, confirmando uma conclusão de Loomba, para quem "os impérios permanecerão" (LOOMBA, 1998, p. 20).

Porém, se não foi no século XIX, via Conrad, que se tentou uma saída para uma consciência social anticolonialista, observamos, um século depois, que essa possibilidade germinou, de alguma forma, através de um poder minoritário, porém, instalado no seio da própria sociedade imperialista: no filme, o exemplo é o das feministas francesas em ação. A esse cisma social, que contrariava um modelo político e econômico estabelecido, se antecipavam ações de comprometimento com outras sociedades, segundo afirma Stam (2003, p. 21) a respeito das contribuições do pós-colonial à realização cinematográfica. Dessa forma, parece que o espírito combativo de Fanon forneceu o alicerce sobre o qual a teoria póscolonial ajudou, especificamente, Coppola a levantar uma ponte, a partir da intertextualidade e verossimilhança extraídas de Conrad: o cineasta, reproduzindo a ficção, alimentado por dados históricos do século XX, retoma o passado para mostrar que o imperialismo norteamericano, no presente, tendo contra si as ações somadas de todas as minorias politizadas e atuantes (o movimento feminista, por exemplo), também pode estar em um campo minado. 


\section{Referências}

APPIAH, Kwame A. Na casa de meu pai: a África na filosofia da cultura. Rio de Janeiro: Contraponto, 1997.

APOCALYPSE Now. Dir. Francis Ford Coppola.EUA, Zoetrope Studios, 1979.1 Videocassete (203min.): LP/VHS/NTsc, son.,color., legendado. Port.

CONRAD, Joseph. O coração das trevas. São Paulo: Martim Claret, 2003.

FANON, Frantz. Do pretenso complexo de dependência do colonizado. In: Pele negra, máscaras brancas. 2.ed. Porto: Paisagem, 1975. Cap.4, p. 98-120 . Os condenados da terra. Rio de Janeiro: paz e Terra, 1973.

LOOMBA, Ania. Colonialism/Postcolonialism. London and Ney York: Routledge, 1998.

MEMMI, Albert. O retrato do colonizado precedido pelo retrato do colonizador. 3.ed. Rio de Janeiro: Paz e Terra, 1977.

SAID, Edward. Territórios sobrepostos, histórias entrelaçadas. In: - Cultura e imperialismo. São Paulo: Companhia das letras, 1990. Cap.1, p. 33-98.

STAM, Robert. Cinema e teoria do $3^{\circ}$ Mundo. In . Introdução à teoria do cinema. Tradução Fernando Mascarello. Campinas: Papirus, 2003. Cap. 13, p. 112-121.

[Recebido em janeiro de 2012 e aceito para publicação em outubro de 2012]

\section{Post colonial theory at the meeting of two narratives}

Abstract: The goal of this study is to conduct a comparative reading between two narrativesthe novel "Heart of darkness" (1898), by Joseph Conrad and the film "Apocalypse now" (1979), directed by Franz Ford Coppola - based on postcolonial theory. The film is an adaptation of that novel, but alters it the context: in the 19th century, the plot takes place in Africa during the period of colonization; in the 20th century, the stage is Asia, over the life of the Viet Nam war (1973-1964). In each one of them, the novel and the film, shows the quest for territorial conquest, through the imposition of seemingly unequal forces. In this sense, it is highlighted the economic and political power of colonizers, at the appropriate time, in different spaces (in the African and Asian continents), giving, in the 20th century, a kind of ideological occupation of Africa update (carried out in the previous century), in which, once abandoned the overseas colonization model, it takes to rise a new format of this economic systemwhich, in the latter case, aims to provide support to the American capitalist system.

Keywords: Colonization. Conflicts. Postcolonial Debate. Imperialism.

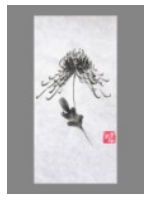

